\title{
Apolipoprotein C2 Measurement
}

National Cancer Institute

\section{Source}

National Cancer Institute. Apolipoprotein C2 Measurement. NCI Thesaurus. Code C100427.

The determination of the amount of apolipoprotein C2 present in a sample. 